\title{
Troglitazone Induces Extracellular Matrix and Cytoskeleton Remodeling in Mouse Collecting Duct Cells
}

\author{
Jaime Corinaldi, Rania Nasrallah, Jordan Clark, Geneviève Paris, Pedro Miura, \\ Bernard J. Jasmin, and Richard L. Hébert \\ Department of Cellular and Molecular Medicine, Kidney Research Centre, Faculty of Medicine, University of Ottawa, \\ Ottawa, ON, Canada K1H 8 M5 \\ Correspondence should be addressed to Richard L. Hébert, rlhebert@uottawa.ca
}

Received 16 September 2011; Revised 9 November 2011; Accepted 15 November 2011

Academic Editor: Beric Henderson

Copyright ( $\odot 2012$ Jaime Corinaldi et al. This is an open access article distributed under the Creative Commons Attribution License, which permits unrestricted use, distribution, and reproduction in any medium, provided the original work is properly cited.

Peroxisome proliferator-activated receptor (PPAR $\gamma)$ has been shown to have a protective role in the nephron through its ability to inhibit a transforming growth factor- (TGF- $\beta$ ) mediated fibrotic response. In contrast, PPAR $\gamma$ was also shown to induce a mesenchymal transformation in epithelial intestinal cells. A fibrotic response in the collecting duct has only recently been established; however, the entire collecting duct has not been fully examined. Inner medullary collecting duct cells (IMCD-K2) and mouse cortical collecting duct cells (M1), representing the cortical and medullary collecting duct, were exposed to 5-10 $\mu \mathrm{M}$ troglitazone for 24 hours. Troglitazone resulted in an elongated morphology, 60\% decreases in E-cadherin and $\beta$-catenin, a 35\% decrease in $\alpha$-catenin, and a 1.5 -fold increase in fibronectin. These effects were not reversed with PPAR $\gamma$ antagonists or affected with PPAR $\gamma$ overexpression. Our results indicate that troglitazone induced a mesenchymal-like transformation in M1 and IMCD$\mathrm{K} 2$ epithelial cells independently of $\operatorname{PPAR} \gamma$.

\section{Introduction}

PPARs are ligand-activated transcription factors that heterodimerize with an RXR receptor. There are currently three cloned PPARs $(\alpha, \gamma$, and $\beta / \delta)$, all of which are expressed in different tissues at various levels and are involved in numerous cellular events including metabolism, differentiation, growth, apoptosis, and tumorigenesis [1-4]. The glitazone receptor, $\operatorname{PPAR} \gamma$, is abundant in brown adipose tissue, intestine, spleen, and kidney. Certain nonsteroidal anti-inflammatory drugs (NSAIDs) and thiazolidinediones (TZDs), of which troglitazone is a member, are synthetic PPARy ligands [5]. Natural ligands include 15-deoxyprostaglandin $\mathrm{J}_{2}\left(\mathrm{PG}_{2}\right)$, certain polyunsaturated fatty acids (PUFAs) such as linoleic acid, and endogenous low-density lipoprotein (LDL) particles.

In the kidney, PPAR $\gamma$ ligands have been shown to have a protective effect in various segments of the nephron including the glomerulus (podocytes and mesangial cells), proximal tubule, and distal tubule. Although PPAR $\gamma$ expression is among the highest in the collecting duct (CD), its role in the CD remains unclear. PPAR $\gamma$ activation by TZDs has been shown to result in oedema through enhanced epithelial sodium cotransporter $(\mathrm{ENaC})$ activity in the $\mathrm{CD}$ [6]. These effects were blocked by amiloride, a CD-specific diuretic. The deletion of PPAR $\gamma$ from the collecting duct, using PPAR $\gamma^{\text {flox/flox }}$ mice, was also successful in reversing the fluid retention. The full impact of PPAR $\gamma$ ligands in the collecting duct requires further characterization as the potential renal protective and antidiabetic effects are promising. Whether PPAR $\gamma$ is an antifibrotic transcription factor is unclear as there have been studies indicating an induction of fibrotic responses by PPAR $\gamma$ ligands. An example of this was found in the intestine where activation of PPAR $\gamma$ was shown to induce a mesenchymal transition in epithelial intestinal cell line [7].

Epithelial cells form organized cell-cell adhesion junctions preventing movement of individual cells and producing a tight epithelial surface. Mesenchymal cells, however, tend 
to be highly motile as they lack this level of organization. The transformation of EMT is described as the process in which epithelial cells that function as ion and fluid transporters lose their epithelial polarity, cellular adhesion molecules, and reorganize their actin cytoskeleton from a cortical bundle formation that supported adhesion molecules into stress fibers containing de novo expressed $\alpha$-smooth muscle actin $(\alpha$-SMA) that supports migration.

EMT has been described in the collecting duct where TGF- $\beta$ induced activation of Smad 3 and ERK1/2 leading to a mesenchymal morphology, increased vimentin and $\alpha$-SMA, and a decrease in E-cadherin and $\beta$-catenin [8]. Expression of E-cadherin has been shown to vary inversely with fibronectin in several diseased states including a unilateral ureteral obstruction (UTO) model, a model which invokes scarring in the collecting duct [9]. This study, however, does not account for a full representation of the collecting duct as it focused on the terminal section.

E-cadherin is an integral, $\mathrm{Ca}^{2+}$-dependent transmembrane adhesion protein that is generally localized at the adheren junctions of epithelial cells and plays an important role in the development and maintenance of renal epithelial polarity. The intracellular domain of E-cadherin is bound to $\beta$-catenin that is bound to $\alpha$-catenin, which in turn links the entire complex to the actin cytoskeleton. Unbound $\beta$ catenin can also function as a component of the Wnt nuclear signaling pathway acting as a coactivator of T-cell factor (TCF)/lymphocyte enhancer factor (LEF) transcription factors $[9,10]$.

PPAR $y$ has been shown to interact with members of the cadherin-catenin cytoskeletal complex through the functional peroxisome proliferator response element (PPRE) described in E-cadherin [11], as well as its catenin-binding domain $(\mathrm{CDB})$ which interacts directly with the TEC/LEF domain in $\beta$-catenin [10]. Studies have shown that PPAR $\gamma$ activation induces proteasomal degradation of $\beta$-catenin as well as a reduction in E-cadherin in several cell types, including hepatocytes [12]. In normal cells, PPAR $\gamma$ can function to suppress Wnt signaling by targeting phosphorylated $\beta$ catenin to the proteasome through a process involving the above-mentioned catenin-binding domain [1].

The overall purpose of this study is to clarify the mechanisms by which TRO/PPAR $\gamma$ alters collecting duct structure and function. We report that TGF- $\beta$ was unable to initiate an epithelial to mesenchymal transformation in the IMCD-K2 and M1 collecting duct cell lines. In contrast, Troglitazone caused morphological changes, decreased E-cadherin, $\alpha$ catenin and $\beta$-catenin, and increased fibronectin. These effects were not reversed with PPAR $y$ antagonists or altered by PPAR $y$ overexpression.

\section{Materials and Methods}

2.1. Cell Culture. The IMCD-K2 cell line is derived from the initial section of the IMCD of an SV40-transgenic mouse. These were a generous gift from Dr. Bruce Stanton (Dartmouth Medical School). IMCD-K2 cells were grown in DMEM : F-12 (1:1) media supplemented with 10\% FBS, $1 \%$ ITS, $1 \%$ Penicillin-Streptomycin, $1 \%$ L-glutamine, and $5 \mu \mathrm{M}$ dexamethasone and were maintained at $5 \% \mathrm{CO}_{2}$ and $37^{\circ} \mathrm{C}$ during culture and treatment. The M-1 cells are a mouse cortical collecting duct cell line (ATCC no. CRL-2038). M1 cells were grown at $37^{\circ} \mathrm{C}$ and $5 \% \mathrm{CO}_{2}$ in DMEM : F- 12 media (1:1), $\mathrm{pH} 7.4$, containing, 5\% FBS, and 1\% Pen-Strep.

2.2. Chemicals and Reagents. Troglitazone (Sigma) is a synthetic PPAR $\gamma$ agonist and was used at $5 \mu \mathrm{M}$ and $10 \mu \mathrm{M}$. Troglitazone is a well-studied synthetic PPAR $y$ agonist. It has high specificity for PPAR $y$ as it does not activate the $\operatorname{PPAR} \delta$ or PPAR $\alpha$ isoforms at a concentration of $25 \mathrm{mM}$ and higher. Troglitazone is a member of a class of antidiabetic drugs that are currently used to improve insulin sensitivity in type 2 diabetics. GW9662 (Cayman Chemicals) is a PPAR $\gamma$ antagonist that covalently modifies $\mathrm{Cys}_{285}$ in PPAR $y$ 's LBD. PPAR $y$ antagonist (T0070907) (Cayman Chemical) covalently modifies Cys 313 thereby modulating PPAR $y$ cofactor recruitment. Both antagonists were used alongside Troglitazone at $10 \mu \mathrm{M}$. $\mathrm{PGJ}_{2}$ (Cayman Chemical) is an endogenous PPAR $\gamma$ agonist. All reagents were dissolved in DMSO to their suggested stock concentrations. Antibodies for $\alpha$-SMA, $\alpha$-catenin, $\beta$-actin, $\beta$-catenin, fibronectin, and Ecadherin were obtained from Sigma-Aldrich (ON, Canada). Anti-PPAR $y$ was obtained from Santa Cruz Biotech (CA, USA). AlexaFluor Phalloidin and DAPI were gifts from Dr. Chris Kennedy (University of Ottawa).

2.3. Western Blot. Following stimulations, protein isolations were performed using RIPA lysis buffer consisting of: RIPA buffer, $10 \mathrm{mM}$ Na fluoride, $1 \mathrm{mM}$ Na pyrophosphate, $100 \mu \mathrm{M}$ Na orthovanadate, $1: 100$ protease inhibitor cocktail (Sigma), and $500 \mu \mathrm{M}$ PMSF. The solution was centrifuged at $10,000 \times \mathrm{g}$ for 10 minutes, and protein was quantified by spectrophotometry using Bradford reagent and denatured by boiling the samples at $95^{\circ} \mathrm{C}$ for $5-10$ minutes. Equal amounts of lysates (50-100 $\mu \mathrm{g})$ were electrophoresed and transferred onto a nitrocellulose membrane (Amersham). The nitrocellulose membrane was blocked in $10 \%$ milk in TBS/T for 1 to 3 hours, and a primary antibody was applied directly to the milk and left overnight. Following three 20minute washes, the primary antibody solution was removed, and the appropriate secondary antibody was applied in $10 \%$ milk-TBS/T for 90 minutes, after which the membranes were washed with TBS/T. The HRP-conjugated secondary antibodies were developed with Pierce SuperSignal chemiluminescent reagent for 5 minutes and exposed to Kodak XOmat Blue XB-1 film as well as digitally exposed using the Alpha Innotech Fluorchem HD2 imaging system.

2.4. Immunofluorescence. Cells were plated on coverslips and allowed to adhere overnight. The culture media was replaced for 24 hours with serum-free DMEM:F-12 and stimulated with TRO and GW9662 for an additional $24 \mathrm{hrs}$. The coverslips were washed with PBS to remove traces of media and fixed for 30 minutes at room temperature in $4 \%$ paraformaldehyde or at $-20^{\circ} \mathrm{C}$ in a $(1: 1)$ methanol-acetone solution. Excess fixative was washed with $\mathrm{PBS} / \mathrm{Mg}^{2+} / \mathrm{Ca}^{2+}$ for $2 \times 5$ minutes. Triton-X at $0.1 \%$ in PBS was used for permeabilization for 30 minutes at room temperature 
followed by $3 \times 5$-minute washes in $\mathrm{PBS} / \mathrm{Mg}^{2+} / \mathrm{Ca}^{2+}$. The coverslips were blocked in 5\% BSA in $0.1 \%$ Triton-X in $\mathrm{PBS} / \mathrm{Mg}^{2+} / \mathrm{Ca}^{2+}$ for 1 hour prior to adding the antibody of choice. All antibodies were diluted in 5\% BSA in 0.1\% Triton-X in $\mathrm{PBS} / \mathrm{Mg}^{2+} / \mathrm{Ca}^{2+}$. Cells were incubated with Phalloidin-FITC for 1 hour at RT in the dark. Next, $3 \times 5$ minute PBS $/ \mathrm{Mg}^{2+} / \mathrm{Ca}^{2+}$ washes were performed prior to the addition of the secondary, $\alpha$-mouse FITC (Sigma) $1: 300$ for 90 minutes or DAPI $(1: 1000)$ for 15 minutes. The coverslips were then mounted in Fluoromount G-mounting media (Southern Biotech). Images were captured using the Zeiss AxioCam of an Axioskop2 MOT Fluorescent microscope.

2.5. PPAR $y$ Overexpression. pcDNA and pcDNA-PPAR $y$ vectors were obtained from Addgene as bacterial stabs. The sizes of each insert were verified with XhoI/HindIII digests. M1 cells were grown to $25 \%$ confluence prior to transfection. $4 \mu \mathrm{g}$ of plasmid DNA was diluted to a volume of $150 \mu \mathrm{L}$ in DMEM and $15 \mu \mathrm{L}$ of Polyfect Transfection Reagent (Qiagen) was added to the solution. The suspension was then incubated at room temperature for 10 minutes, mixed with $1 \mathrm{~mL}$ of culture media containing $0.1 \%$ ampicillin, and added to the culture plate. This was repeated 48 hours later for the final 24 hours of the 72 hours transfection period.

2.6. Statistics. GraphPad Prism v4.03 was used to plot and analyse the data collected. Values are expressed as means \pm standard error of the mean (S.E.M.). An unpaired $t$-test was used to assess statistical significance between selected experimental groups. A one-sample $t$-test was performed against a hypothetical value of 1.0 for all groups as the values represented fold controls where the control group all had values of 1.0. Statistical analysis for multiple comparisons was done using one-way ANOVA corrected with Bonferroni's posttest. A $P$ value $\leq 0.05$ was regarded as statistically significant.

\section{Results}

3.1. TRO Induces Morphological Changes in M1 Cells. The presence of PPAR $y$ in both the M1 and IMCD-K2 cell lines was verified through Western blot and RT-PCR (Figure 1) with PPAR $\gamma$ being successfully overexpressed in M1 cells as seen in Figure 1(a). The general effects of TZDs in the kidney have been protective; however, the treatment of M1 cells with TRO resulted in a decrease in cell-to-cell contact, disorganization of the F-actin cytoskeleton filament network, and a less rounded, elongated spindle-like shape at $5 \mu \mathrm{M}$ and $10 \mu \mathrm{M}$, visualized through FITC-conjugated Phalloidin (Figure 2). These morphological changes were not attenuated by the PPAR $\gamma$ antagonist GW9662 at $10 \mu \mathrm{M}$ with the same order of disorganization and cell elongation being observed after cotreatment in Figures 2(d) and 2(f).

3.2. Troglitazone Induces Cytoskeleton Reorganization in the IMCD-K2 and M1 Collecting Duct Cell Lines. Along with the aforementioned morphological changes, treatment of IMCD-K2 and M1 cells with TRO resulted in a decrease

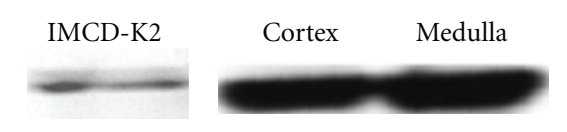

(a)

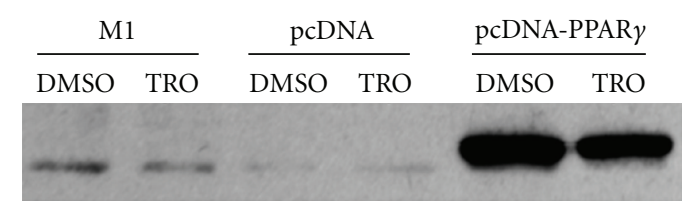

(b)

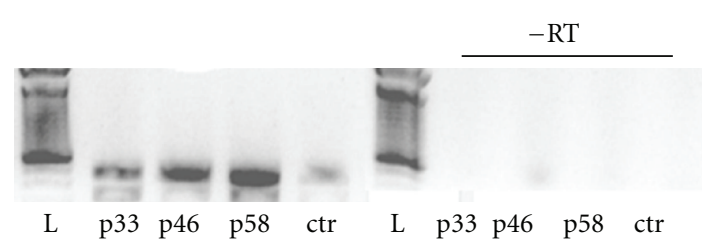

(c)

FIGURE 1: PPAR $\gamma$ is present in the IMCD-K2 and M1 collecting duct cell lines. (a) Western blot analysis of PPAR $y$ detected a band at $67 \mathrm{kDa}$ in IMCDK2 cells, also shown in mouse cortex and medulla lysates used as a positive control. (b) In M1 cells, endogenous PPAR $y$ levels as well as those of the pcDNA plasmid control and pcDNA-PPAR $\gamma$ overexpression samples are shown, included for each are samples treated for 24 hours with DMSO (vehicle) or $10 \mu \mathrm{M}$ troglitazone (TRO). (c) In different passages of M1 cells (ctr, P33, 46, and 48), RT-PCR analysis produced a 400 bp product corresponding to PPAR $\gamma$ detected on $1 \%$ agarose gel. The (RT-) samples were used as a negative control. Lanes identified as $\mathrm{L}$ contain DNA ladder.

in several epithelial adhesion markers. Figure 3 shows the analysis of $\alpha$-smooth muscle actin ( $\alpha$-SMA) in M1 cells and vascular smooth muscle cells (VSMC, positive control). As seen, $\alpha$-SMA was not detectable in M1 cells even upon TRO stimulation, whereas a strong signal was obtained by Western blotting and immunofluorescence in VSMC. By immunofluorescence, very weak staining for $\alpha$-SMA was observed in image B only upon a prolonged exposure up to $500 \mathrm{~ms}$, confirming the minimal TRO effect. This response was not strong enough for detection by Western blot, even in $100 \mu \mathrm{g}$ of lysate. In comparison, Figures 4(a) and 7(a) show a clear decrease in E-cadherin and increase in the intensity of fibronectin staining through immunofluorescence in response to TRO. Figures 4(b) and 4(c) show a 60\% drop in E-cadherin with TRO in M1 and IMCD-K2 cells. Treatment with a lower dose of TRO resulted in a 30\% drop in Ecadherin. The same trend is shown in Figure 5 with a $60 \%$ reduction in $\beta$-catenin levels after 24 -hour TRO treatment, and a $30 \%$ reduction in $\alpha$-catenin (Figure 6). Conversely, an upregulation of fibronectin was obtained in response to 24-hour TRO (Figures 7(b) and 7(c)), near 2-fold in M1 cells, and 1.5-fold in IMCD-K2 cells. In comparison, Figure 8 illustrates the response of $\mathrm{M} 1$ cells to $\mathrm{PGJ}_{2}$. As shown, 24-hour treatment with $0.5 \mu \mathrm{M} \mathrm{PGJ} 2$ increased E-cadherin and fibronectin levels to $1.5-2$-fold of control. A numerical increase in $\beta$-catenin was also observed. 


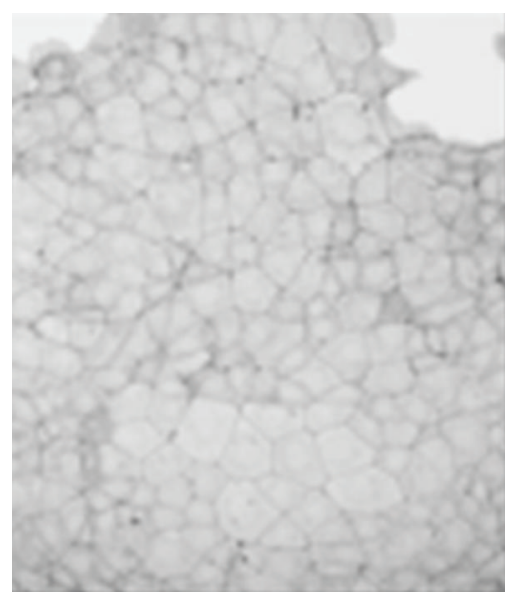

(a)

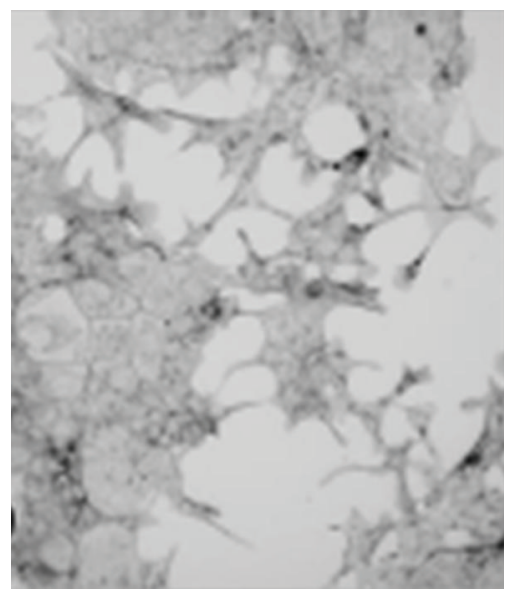

(d)

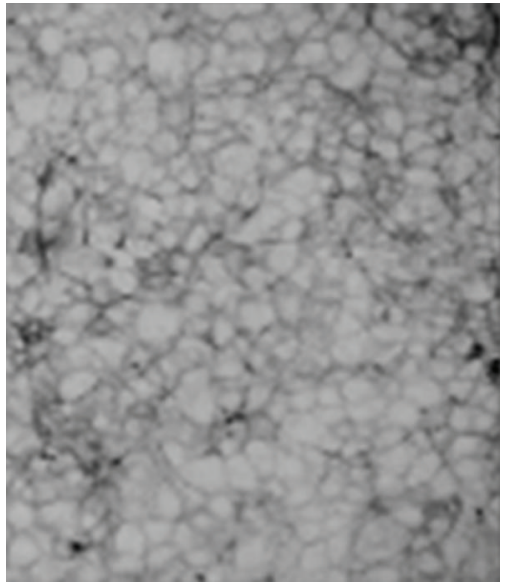

(b)

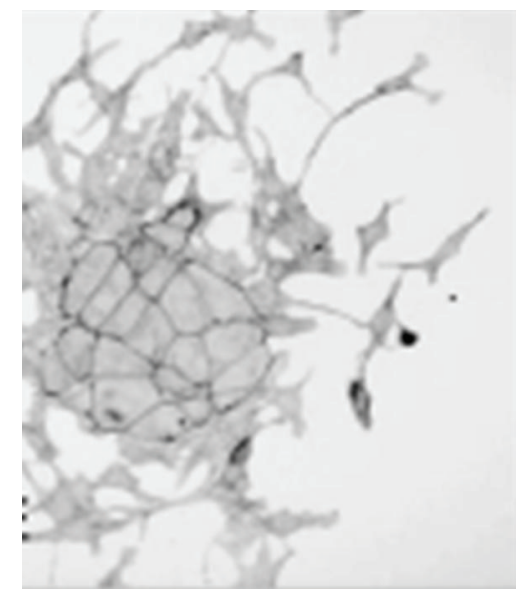

(e)

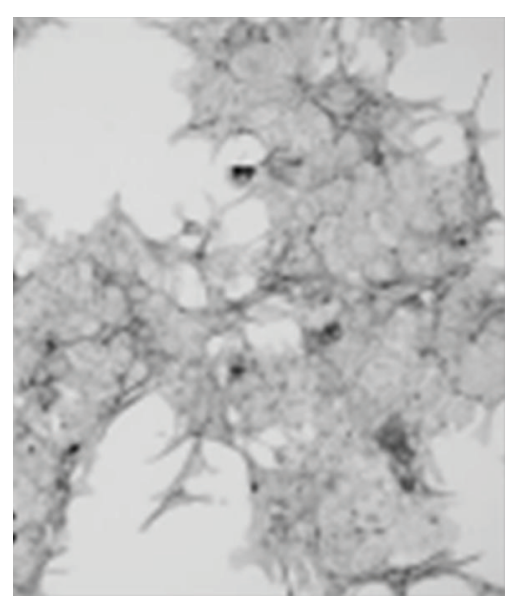

(c)

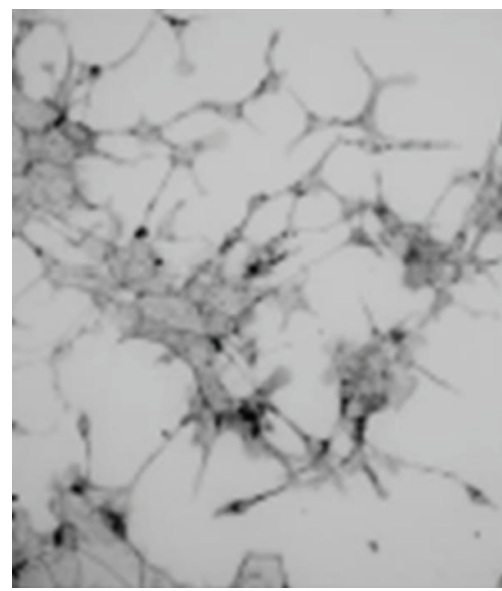

(f)

FIGURE 2: Troglitazone induces morphological changes in M1 cells independent of PPAR $\gamma$. Images of F-actin filaments stained with FITCconjugated phalloidin are shown, in M1 cells stimulated for 24 hours with (a) DMSO (vehicle), (b) $10 \mu$ M GW9662 (PPAR $\gamma$ antagonist), (c) $5 \mu \mathrm{M}$ troglitazone (TRO), (d) GW9662 and $5 \mu \mathrm{M}$ TRO, (e) $10 \mu \mathrm{M}$ TRO, and (f) GW9662 and $10 \mu \mathrm{M}$ TRO. Magnification 100x.

3.3. TRO-Mediated Effects in the M1 Collecting Duct Cell Line Are PPAR $\gamma$ Independent. TZDs are known to induce several PPAR $\gamma$-independent effects. In our study PPAR $\gamma$ antagonists GW9662 and T0070907 had no effect on E-cadherin (Figure $4(\mathrm{~d})$ ), $\beta$-catenin (Figure $5(\mathrm{c})$ ), or fibronectin (data not shown). However, as shown in Figure 6, T0070907 resulted in a further 2 -fold reduction in $\alpha$-catenin levels, but this was not statistically significant. The overexpression of PPAR $\gamma$ in M1 cells was performed to see whether an enhancement of the abovementioned effects could be observed. However, PPAR $\gamma$ overexpression did not significantly change the $50 \%$ decrease in E-cadherin in nontransfected M1 cells compared to cells transfected with the pcDNA plasmid control and the pcDNA-PPAR $\gamma$ vector insert (Figure 4(e)). As seen in Figure 7(d) the 1.5-fold increase in fibronectin in nontransfected and plasmid control transfected cells was not increased with PPAR $\gamma$ overexpression in pcDNA-PPAR $\gamma$ transfected cells, instead yielding a modest 1.3-fold increase in fibronectin, lower than in nontransfected cells. Taken together these results portray a system in which PPAR $\gamma$ does not mediate TRO responses in collecting duct cells.

It should also be noted that the transformation of the epithelial CD cell lines via a cytotoxic response is unlikely. An inhibition of growth along with p38 activation was described in a previous study; however, no oxidative stress (ROS generation) or cell death (cleaved caspase-3 expression) were observed [13]. The reduction in cell number seen with TRO compared to control can be primarily attributed to the aforementioned decrease in proliferation. TRO is also known to drop $\mathrm{pH}$ levels [14]; however, we did not observe any significant levels of acidosis in our cell culture media in a $48 \mathrm{hr}$ period.

\section{Discussion}

4.1. PPARy in the Collecting Duct. PPAR $y$ has previously been detected in vivo in the medullary and cortical collecting duct $[13,15]$ and was present in both IMCD-K2 and 


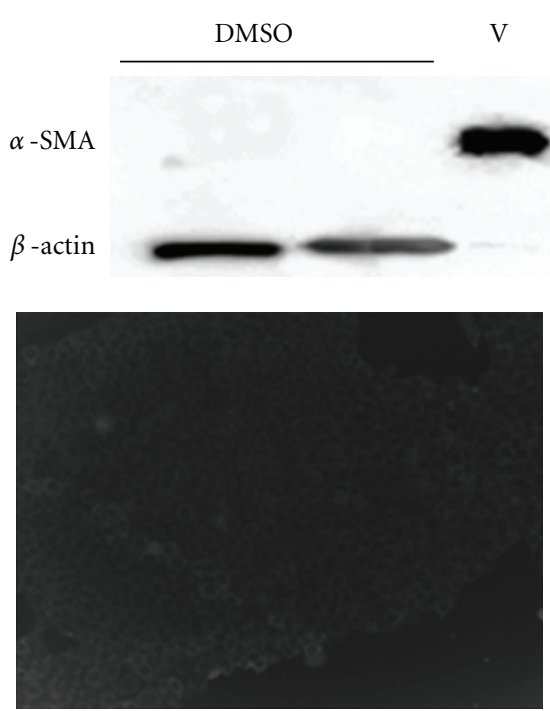

(a)

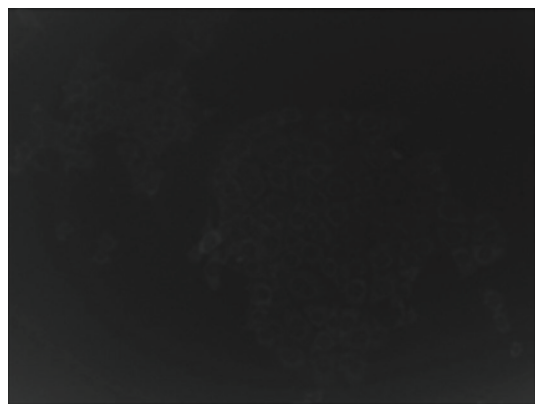

(c)

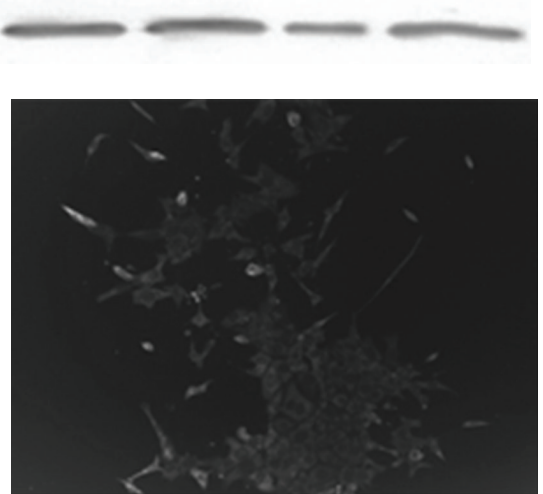

(b)

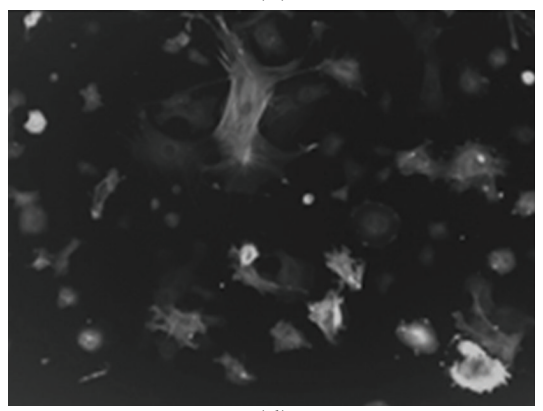

(d)

Figure 3: Troglitazone does not induce $\alpha$-SMA expression in M1 cells. In the upper panel, $\alpha$-smooth muscle actin ( $\alpha$-SMA) was assessed by Western blotting in $100 \mu$ g lysates from M1 cells treated with DMSO, confirming the absence of $\alpha$-SMA, vascular smooth muscle cells (V) were used as a positive control, and 4 lanes of M1 cells treated with $10 \mu \mathrm{M}$ troglitazone (TRO) for 24 hours. In the lower panel, $\alpha$-SMA was assessed by immunofluorescence. Images are shown of M1 cells stimulated with (a) DMSO and (b) $10 \mu \mathrm{M}$ troglitazone (TRO) for 24 hours, (c) antimouse FITC conjugated secondary as a negative control, and (d) vascular smooth muscle cells were used as a positive control. Magnification 100x.

M1 cells in our study. To our knowledge the only other studies on PPAR $y$ and the collecting duct indicate that it may be involved in sodium and fluid balance, as seen with the PPAR $\gamma$ knockout model reversing the oedemic effects resulting from TZD treatment $[6,16]$. The use of $\operatorname{PPAR} \gamma$ agonists, specifically TZDs, on the other hand, has raised interest in several fields of research due to their potential antifibrotic and antitumorigenic effects. Troglitazone has been shown to suppress TGF- $\beta$-induced SMAD2/3 phosphorylation, thereby inhibiting EMT in human retinal pigment epithelial cells independent of PPAR $\gamma$ [17]. It has also been suggested that the antiproliferative effects of TZDs in cancer cells are also independent of PPAR $\gamma$ activation as TZD analogs, unable to activate PPAR $\gamma$, retain the ability to induce apoptosis at an equal potency in several cancer cell lines. Nonetheless, there is an emerging view that some antitumorigenic effects are partially PPAR $\gamma$ dependent, whereas most are independent of the receptor $[1,18]$.

In our studies PPAR $y$ was successfully overexpressed in M1 cells. The increased PPAR $y$ levels did not appear to alter cell morphology alone; however, stimulation with
TRO in over-expressed cells resulted in a similar phenotype as in nontransfected M1 cells. Generally, PPARy overexpression alone is sufficient to induce a cellular response without the use of an agonist as seen in pancreatic islets where overexpression of PPAR $y$ protein suppressed insulin secretion induced by stimulatory concentrations of glucose $[19,20]$. This was also seen in rat livers where PPAR $y$ was over-expressed using an additional adenoviral vector (AdPPAR $\gamma)$, resulting in significantly lower levels of fibrosis compared to controls [21]. Troglitazone has been shown to act through both PPAR-dependent and -independent mechanisms in epithelial cells. For instance, in porcine renal epithelial tubules, TZDs can modulate the pathways influencing glucose and glutamine metabolism, as well as cellular acidosis favoring reduced plasma glucose in vivo [14,22]. This alteration in cellular acidosis and glutamine metabolism was verified in $\mathrm{pH}$-sensitive lung carcinoma cells where TZD-dependent PPAR $y$ activation was verified; however, the primary effects of the study were still independent of this activation, instead involving PKC/ERK. The task remains to decipher which effects obtained with TZDs are PPAR $y$ 


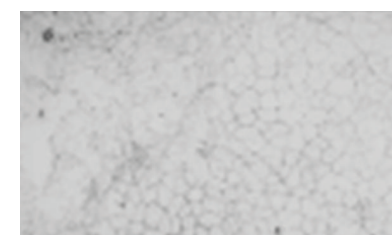

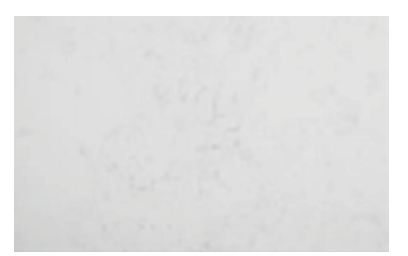

(a)

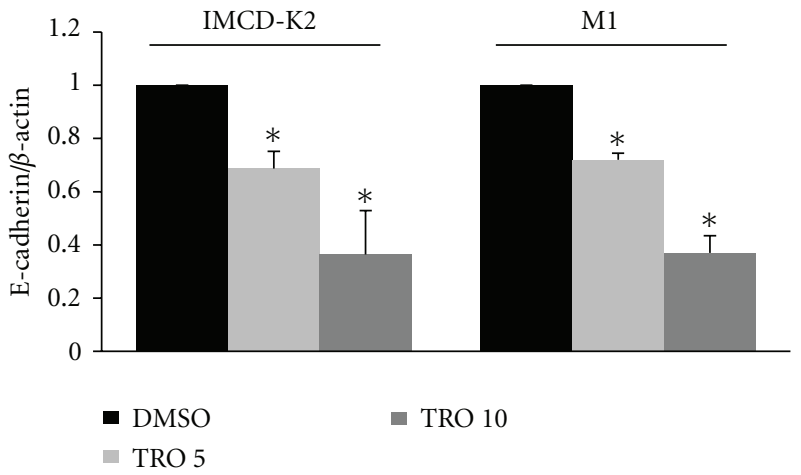

(c)

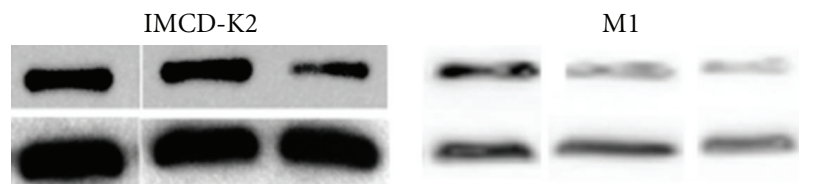

(b)

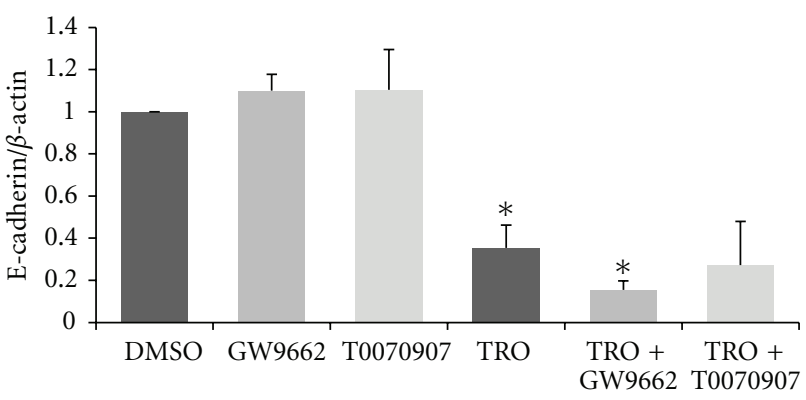

(d)

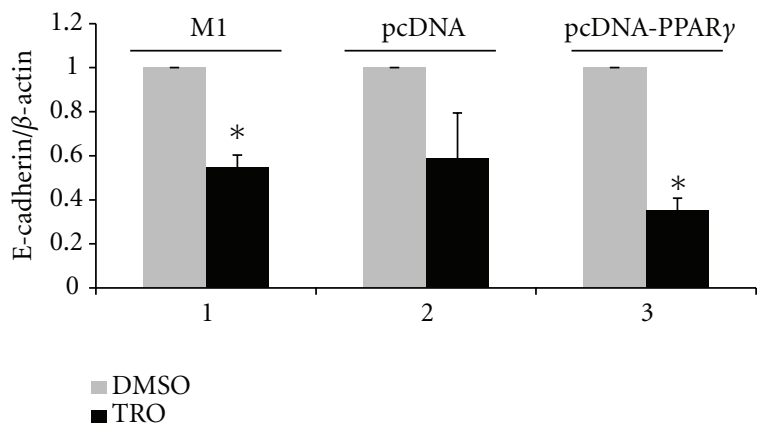

(e)

FIgURE 4: Troglitazone attenuates E-cadherin expression in IMCD-K2 and M1 cells. In (a) E-cadherin is detected by immunofluorescence in M1 cells stimulated with DMSO (vehicle, upper) and $10 \mu \mathrm{M}$ troglitazone (lower) for 24 hours (magnification 100x). In (b) IMCD-K2 and M1 cells were treated with DMSO (vehicle) or troglitazone (TRO), and a representative Western blot is shown for E-cadherin (upper bands) and corresponding $\beta$-actin (lower bands). In (c) the corresponding densitometric analysis is shown with data presented as mean \pm S.E.M. $P \leq 0.05\left(^{*}\right)$. In $(\mathrm{d})$ a densitometric analysis of E-cadherin is shown for M1 cells treated with $10 \mu \mathrm{M}$ TRO in the presence or absence of the PPAR $\gamma$ antagonists GW9662 and T0070907. In (e) the densitometric analysis is shown for E-cadherin in M1 cells treated with DMSO or $10 \mu \mathrm{M}$ TRO with endogenous PPAR $\gamma$ as well as those expressing the control pcDNA plasmid and pcDNA-PPAR $\gamma$ overexpression. Data presented as mean \pm S.E.M. $P \leq 0.05\left(^{*}\right)$.

mediated and how they are interconnected with the PPAR $\gamma$ independent pathways to fully understand how these drugs operate.

4.2. TGF- $\beta$ and EMT in IMCD-K2 and M1 Cells. TGF- $\beta$ was unable to induce EMT in either cell line. This was surprising as the IMCD-3 cell line, representing the terminal section of the inner medulla has recently been shown to undergo EMT upon stimulation with TGF- $\beta$. Although our stimulation was extended to $96 \mathrm{hrs}$, the high levels of E-cadherin and $\beta$ catenin may have protected the tight junctions, requiring a longer time point to achieve the initial disruptions in cell contact required to initiate the expression of mesenchymal markers. The enhanced growth rate of the immortalized cell lines may have also contributed to the lack of a response. Both TGF- $\beta$ receptors as well as endogenous cytokine have 


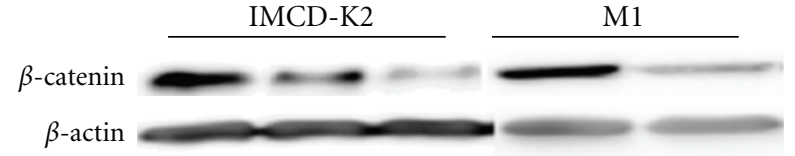

(a)

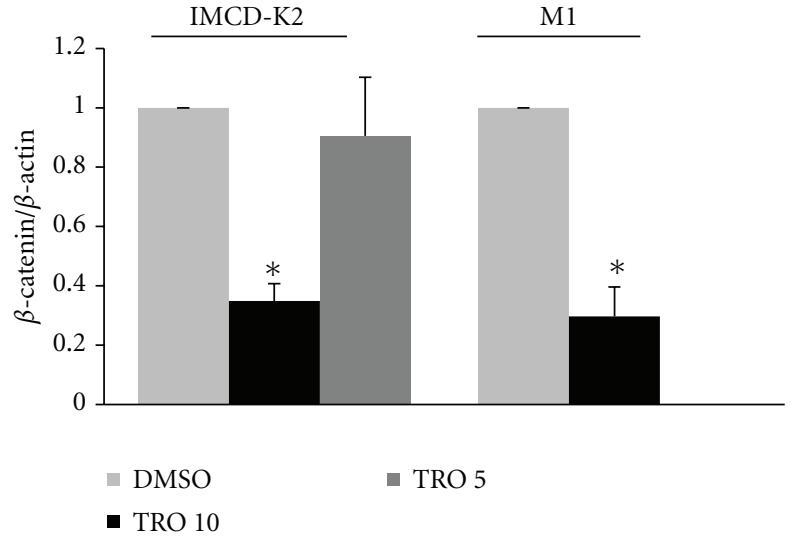

(b)

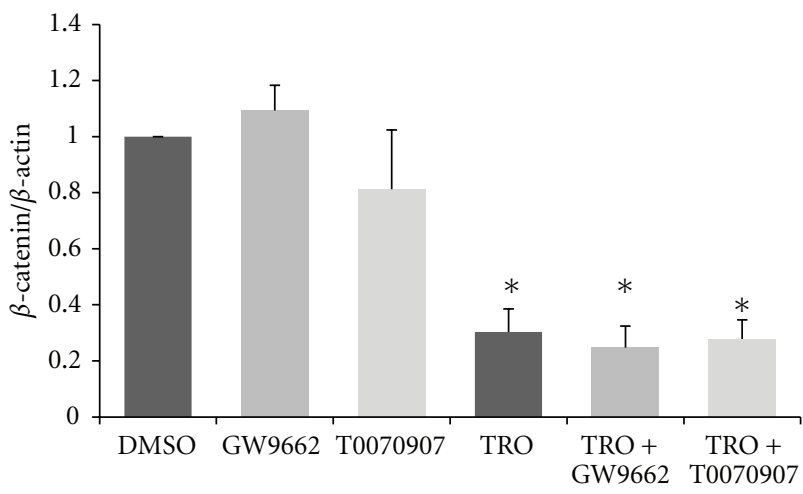

(c)

FIGURE 5: Troglitazone attenuates $\beta$-catenin expression in IMCD$\mathrm{K} 2$ and $\mathrm{M} 1$ cells. IMCD-K2, and M1 cells were treated with DMSO (vehicle) or troglitazone (TRO), and in (a) a representative Western blot is shown for $\beta$-catenin and corresponding $\beta$-actin. In (b) the corresponding densitometric analysis is shown with data presented as mean \pm S.E.M. $P \leq 0.05\left({ }^{*}\right)$. In (c) a densitometric analysis of $\beta$-catenin is shown for M1 cells treated with $10 \mu \mathrm{M}$ TRO in the presence or absence of the PPAR $\gamma$ antagonists GW9662 and T0070907.

been previously characterized in both cell lines [23, 24]. The inability to induce EMT prevented a full assessment of whether PPAR $y$ activation could have reversed these effects, which would have confirmed a protective role for the transcription factor in collecting duct cells.

4.3. Troglitazone and Cell Morphology. TRO caused a loss in cell-to-cell contact and an elongated spindle-like phenotype in a percentage of the treated cell population. The changes in cell shape appear to be PPAR $\gamma$ independent as GW9662 did not restore normal morphology or any cell-to-cell contact. Additionally the agonist may have resulted in a further disruption of cell integrity with TRO cotreatment. TRO may

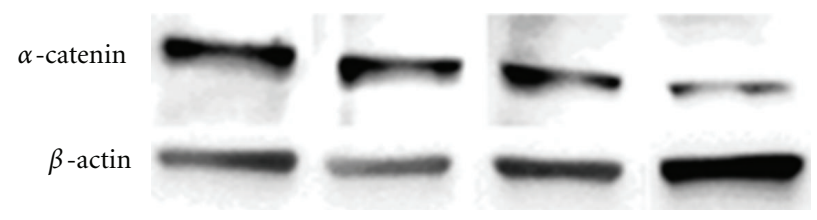

(a)

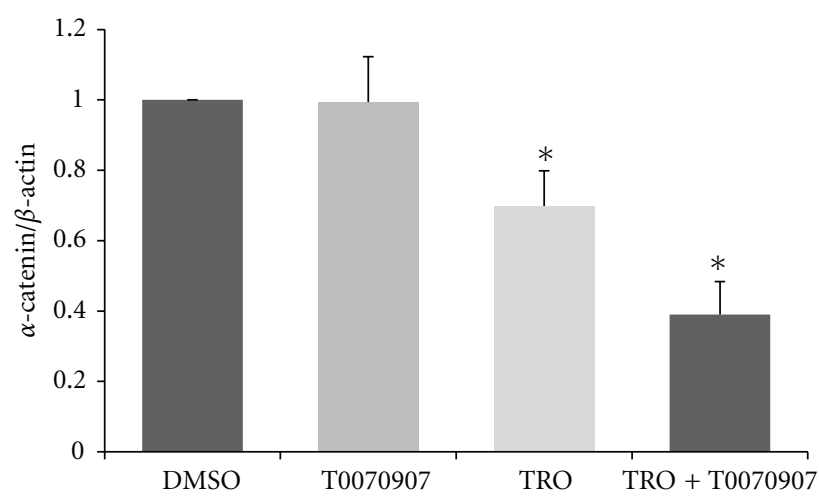

(b)

Figure 6: Troglitazone attenuates $\alpha$-catenin in M1 cells. M1 cells were treated with $10 \mu \mathrm{M}$ troglitazone (Tro) in the presence or absence of the PPAR $\gamma$ antagonist T0070907. Western blot was performed for $\alpha$-catenin, and the results were normalized to $\beta$ actin. (a) A representative blot is shown, and (b) the corresponding densitometric analysis. Data presented as mean \pm S.E.M. $P \leq 0.05$ $(*)$.

be acting through both PPAR $\gamma$-dependent and -independent pathways in inducing the aforementioned changes in morphology; however, with no partial reversal upon antagonism, it is more likely that a PPAR $\gamma$-independent pathway is able to fulfill the necessary steps to obtain the phenotype observed. PKC/Akt and MAP kinase activation may be involved as TZDs have been shown to enhance PKC/Akt phosphorylation in both diabetic and nondiabetic rats and MAP kinase activation is a well-characterized PPAR $\gamma$-independent response to TZDs [10]. This elongated phenotype was absent in populations that were able to reach confluence. This generally occurred if cells were stimulated with TRO at a confluence greater than $75 \%$. Even with an inhibition in growth, highly populated plates were able to proliferate in close proximity. TRO does not appear to be able to alter morphology and initiate cell-to-cell contact disruption in confluent layers of IMCD-K2 and M1 cells. Similarly, intact tubular epithelial layers do not undergo EMT upon TGF- $\beta$ stimulation either; however, loss of epithelial integrity (subconfluence, wounding, and contact disassembly by $\mathrm{Ca}^{2+}$ removal) restores the ability of the monolayer to undergo a mesenchymal transformation $[25,26]$. This suggests that there may be a similar phenomenon observed in our study, with Troglitazone requiring a disruption in the cell monolayer in order to induce the morphological changes characterized.

4.4. Troglitazone and the ECM/Cytoskeleton. TRO induced decreases in epithelial adhesion markers such as E-cadherin, 

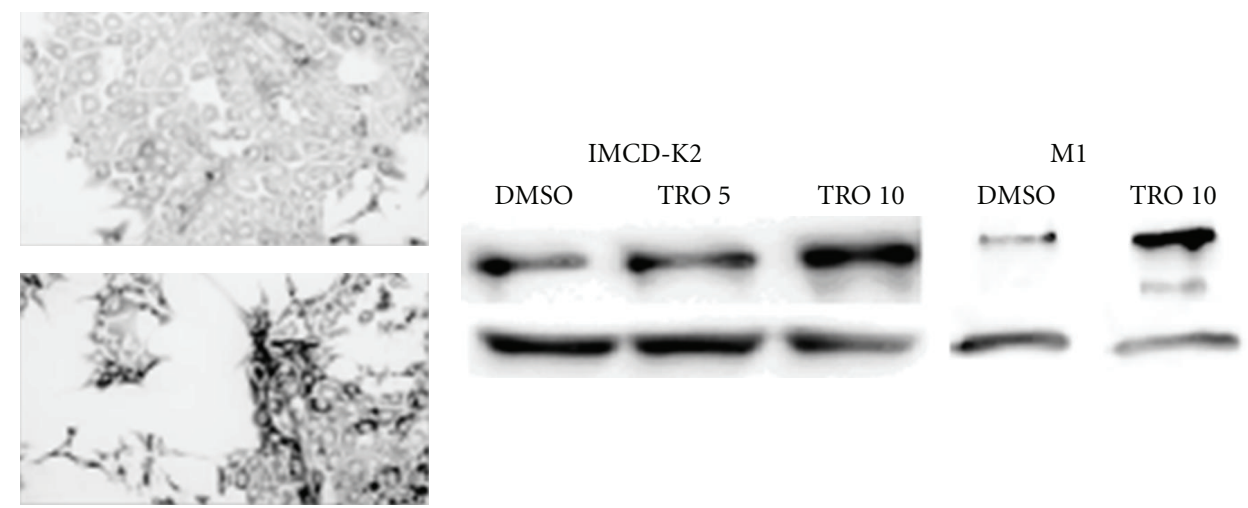

(a)

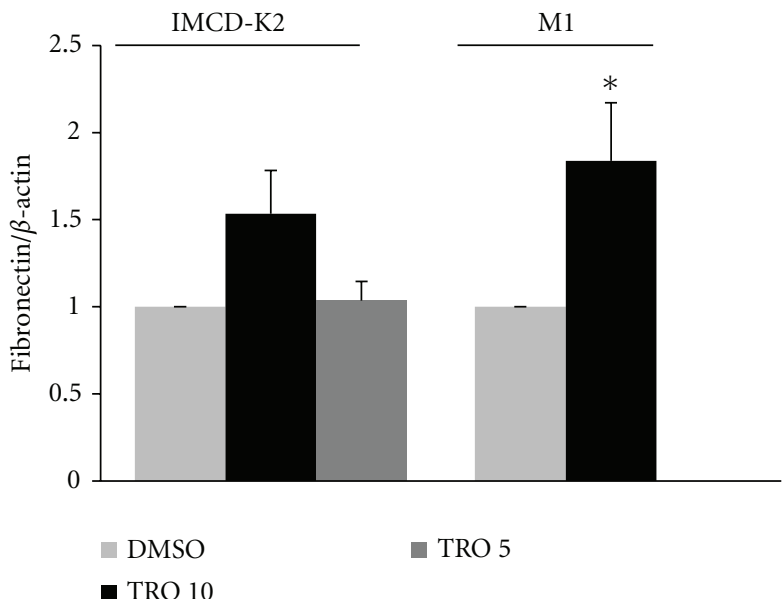

(c) (b)

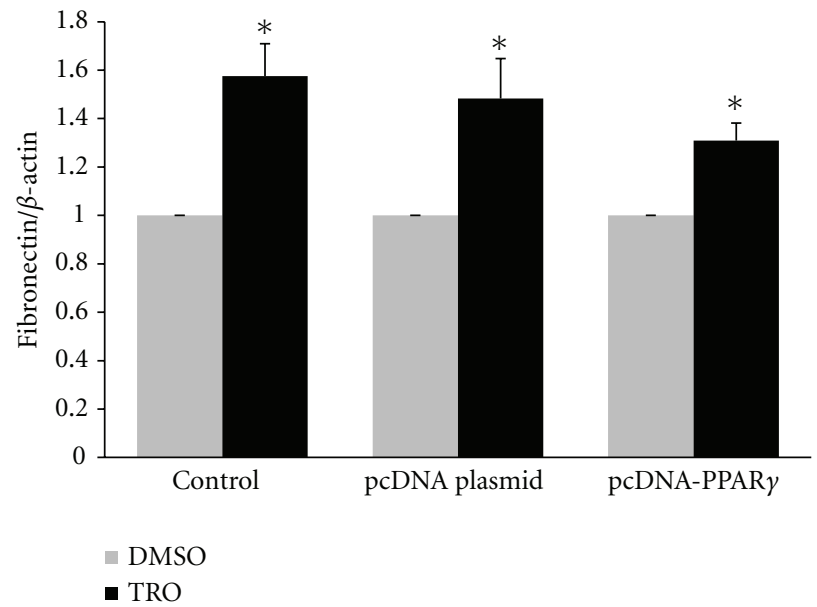

(d)

FIGURE 7: Troglitazone increases fibronectin expression in IMCD-K2 and M1 cells. In (a) fibronectin is detected by immunofluorescence in M1 cells stimulated with DMSO (vehicle, upper) and $10 \mu \mathrm{M}$ troglitazone (lower) for 24 hours (magnification 100x). In (b) IMCD-K2 and M1 cells were treated with DMSO (vehicle) or troglitazone (TRO), and a representative Western blot is shown for fibronectin (upper bands) and corresponding $\beta$-actin (lower bands). In (c) the corresponding densitometric analysis is shown with data presented as mean \pm S.E.M.

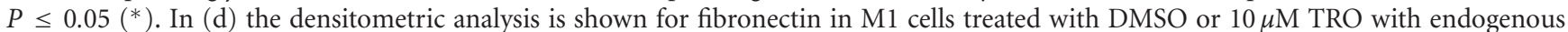
PPAR $\gamma$ as well as those expressing the control pcDNA plasmid and pcDNA-PPAR $\gamma$ overexpression. Data presented as mean \pm S.E.M. $P \leq 0.05$ $(*)$.

$\alpha$-catenin, and $\beta$-catenin. TRO also caused an increase in fibronectin protein but did not trigger de novo $\alpha$-SMA expression, the hallmark of myofibroblast generation. $\mathrm{PGJ}_{2}$ on the other hand increased E-cadherin, $\beta$-catenin, and fibronectin levels. This suggests that PPAR $\gamma$ activation in vivo, as $\mathrm{PGJ}_{2}$ is a supposed endogenous ligand of PPAR $\gamma$, may counteract the decreases in epithelial markers observed in vitro with a synthetic ligand. These inconsistencies among PPAR $\gamma$ ligands are mirrored in MCF-7 breast cancer cells where conjugated linoleic acid, which acts as a PPAR $\gamma$ agonist, also caused an upregulation and redistribution of $\beta$-catenin and E-cadherin [27]. E-cadherin has been shown to have a functional PPRE [11] suggesting that PPAR $\gamma$ stimulation may result in an increase in E-cadherin levels. Although the $\mathrm{PGJ}_{2}$ and TRO results contradict one another, TRO stimulation may still involve a PPAR response element since a PPAR $\gamma$ co-repressor complex could have bound to E-cadherin's PPRE, preventing further transcription and thereby translation of the E-cadherin protein. A core function of p120-catenin is to regulate cadherin stability and turnover by controlling cadherin entry into the degradative endocytic pathways $[1,28]$. The decrease in protein levels could have been due to the prevention of E-cadherin turnover and enhanced degradation. A closer look at p120catenin would clarify whether TRO's effects on E-cadherin were secondary, preventing the regeneration of E-cadherin protein, as opposed to causing the direct degradation of the adheren marker.

Nonetheless, the decrease in E-cadherin in our study occurs independently of PPAR $\gamma$. The PPAR $\gamma$ antagonists T0070907 and GW9662 did not reverse the decrease observed. Overexpression of PPAR $\gamma$ did not alter the drop in E-cadherin levels upon TRO stimulation either. The opposing effects of the two agonists, TRO and $\mathrm{PGJ}_{2}$, create another argument that the effects of at least one of the ligands are PPAR $\gamma$ independent. Another explanation is that one ligand activates PPAR $y$ at a higher capacity than the other as this paradox has been shown to induce opposing effects in breast cancer tissue, depending on the magnitude of PPAR $\gamma$ activation in terms of cellular proliferation, 


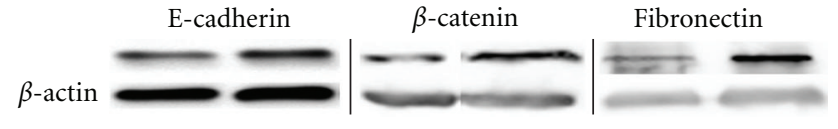

(a)

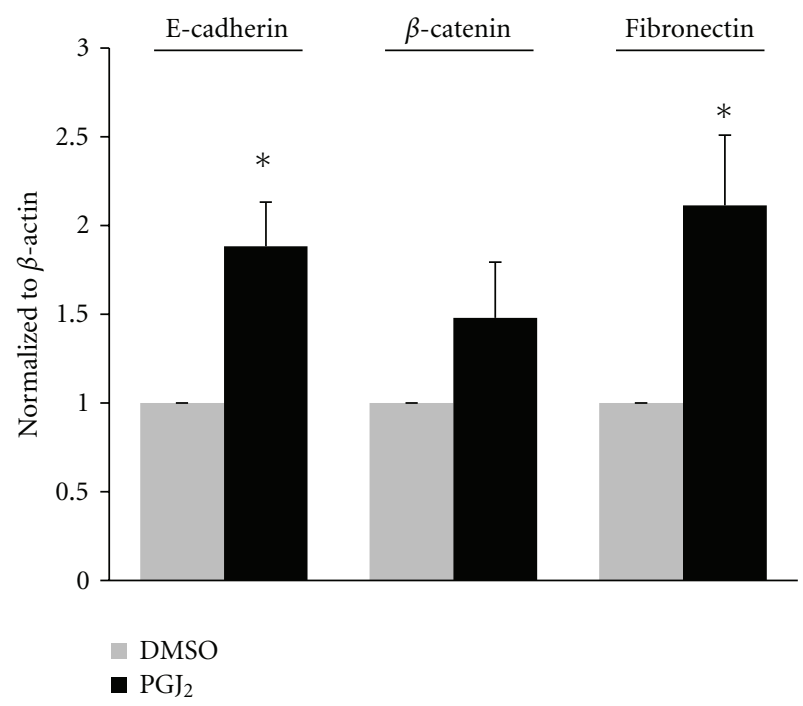

(b)

Figure 8: $\mathrm{PGJ}_{2}$ increases ECM-cytoskeleton proteins in M1 cells. $\mathrm{M} 1$ cells were treated with $0.5 \mu \mathrm{M} \mathrm{PGJ}_{2}$ for 24 hours. Western blot was performed for E-cadherin, $\beta$-catenin, and Fibronectin. (a) The results were normalized to $\beta$-actin $(n=4)$ and (b) a densitometric analysis is shown. Data presented as mean \pm S.E.M. $P \leq 0.05\left(^{*}\right)$.

differentiation, and apoptosis of cancer cells and tumors [1]. For example, lower concentrations increased cellular proliferation, whereas higher concentrations blocked cell growth.

It should be noted that the $50 \%$ reduction in $\beta$-catenin may have not only led to the destabilization of adheren junctions and loss of cell-to-cell contact but also to decreases in $\beta$-catenin activity as an LEF/TCF transcription factor, possibly accounting for some of the other effects observed upon TRO stimulation. Whether any one effect can be directly linked to catenin signaling would require a full restoration of $\beta$-catenin levels. TRO also caused a decrease in $\alpha$-catenin in M1 cells. This decrease was not reversed by T0070907 suggesting the degradation of $\alpha$-catenin to be independent of PPAR $\gamma$ activation as well. Generally $\alpha$ catenin is thought of as a static link between the cadherincatenin chain and actin cytoskeleton; however, new roles for $\alpha$-catenin are being described as $\alpha$-catenin has been shown to exist as a monomer or a dimer with monomeric $\alpha$-catenin binding more strongly to E-cadherin- $\beta$-catenin and the dimer preferentially binding to actin filaments [29]. Determining the proportion of monomeric to dimerized $\alpha$ catenin affected by TRO stimulation may shed light on the local regulation of actin assembly and organization at sites of cadherin-mediated cell-cell adhesion.

Fibronectin was upregulated by $\mathrm{TRO}$ and $\mathrm{PGJ}_{2}$. In a previous study we showed that lower concentrations of TRO had no effect on fibronectin in collecting duct cells [13].
This provides a further argument for the concentration dependence of TRO actions though the effect of fibronectin seems to be mainly PPAR $\gamma$ independent (no effect of PPAR $\gamma$ antagonism or overexpression). Generally TZDs have been shown to reverse fibronectin expression in diseased states, as in human lung carcinoma cells [3], in human cortical fibroblasts [30], in TGF- $\beta$-treated glomerular mesangial cells [31], and in diabetic mice [32]. Nonetheless, the complex nature and inconsistencies of PPAR $\gamma$ activation and function in terms of its ligands are seen throughout the literature. An inverse relation between the adhesion molecule E-cadherin and the matrix protein fibronectin has been established in many diseased states, a trend observed in this study suggesting that the collecting duct may be altered upon stimulation with Troglitazone.

\section{Conclusion}

PPAR $\gamma$ is present in the collecting duct; however, the use of TRO, a potent synthetic ligand, resulted in structural changes independent of its target receptor. These effects were not replicated with the use of $\mathrm{PGJ}_{2}$, a proposed endogenous PPAR $\gamma$ ligand. PPAR $\gamma$ overexpression did not accentuate any of the effects obtained from stimulation with TRO. Taken together the data suggest that TRO can alter ECM and cytoskeletal marker expression in the CD leading to a partial epithelial to mesenchymal-like transformation, independent of PPAR $\gamma$. The beneficial effects of PPAR $\gamma$ ligands in other diseased systems highlight the relevance of this study and underline the importance of fully understanding the effects of these drugs to improve their use and specificity.

\section{References}

[1] F. S. Chou, P. S. Wang, S. Kulp, and J. J. Pinzone, "Effects of thiazolidinediones on differentiation, proliferation, and apoptosis," Molecular Cancer Research, vol. 5, no. 6, pp. 523530, 2007.

[2] S. Han and J. Roman, "Peroxisome proliferator-activated receptor $\gamma$ : a novel target for cancer therapeutics?" Anti-Cancer Drugs, vol. 18, no. 3, pp. 237-244, 2007.

[3] S. Han, J. D. Ritzenthaler, H. N. Rivera, and J. Roman, "Peroxisome proliferator-activated receptor- $\gamma$ ligands suppress fibronectin gene expression in human lung carcinoma cells: involvement of both CRE and Sp1," American Journal of Physiology, vol. 289, no. 3, pp. L419-L428, 2005.

[4] U. Panchapakesan, S. Sumual, C. A. Pollock, and X. Chen, "PPAR $\gamma$ agonists exert antifibrotic effects in renal tubular cells exposed to high glucose," American Journal of Physiology Renal Physiology, vol. 289, no. 5, pp. F1153-F1158, 2005.

[5] D. Bishop-Bailey and T. D. Warner, "PPARgamma ligands induce prostaglandin production in vascular smooth muscle cells: indomethacin acts as a peroxisome proliferator-activated receptor-gamma antagonist," FASEB Journal, vol. 17, pp. 1925-1927, 2003.

[6] Y. Guan, C. Hao, D. R. Cha et al., "Thiazolidinediones expand body fluid volume through PPAR $\gamma$ stimulation of ENaCmediated renal salt absorption," Nature Medicine, vol. 11, no. 8, pp. 861-866, 2005.

[7] L. Chen, B. M. Necela, W. Su et al., "Peroxisome proliferatoractivated receptor $\gamma$ promotes epithelial to mesenchymal 
transformation by Rho GTPase-dependent activation of ERK1/2," Journal of Biological Chemistry, vol. 281, no. 34, pp. 24575-24587, 2006.

[8] L. Ivanova, M. J. Butt, and D. G. Matsell, "Mesenchymal transition in kidney collecting duct epithelial cells," American Journal of Physiology, vol. 294, no. 5, pp. F1238-F1248, 2008.

[9] K. Surendran, S. P. McCaul, and T. C. Simon, "A role for Wnt4 in renal fibrosis," American Journal of Physiology, vol. 282, no. 3, pp. F431-F441, 2002.

[10] J. Liu, H. Wang, Y. Zuo, and S. R. Farmer, "Functional interaction between peroxisome proliferator-activated receptor $\gamma$ and $\beta$-catenin," Molecular and Cellular Biology, vol. 26, no. 15, pp. 5827-5837, 2006.

[11] J. S. Annicotte, I. Iankova, S. Miard et al., "Peroxisome proliferator-activated receptor $\gamma$ regulates E-cadherin expression and inhibits growth and invasion of prostate cancer," Molecular and Cellular Biology, vol. 26, no. 20, pp. 7561-7574, 2006.

[12] C. Sharma, A. Pradeep, L. Wong, A. Rana, and B. Rana, "Peroxisome proliferator-activated receptor $\gamma$ activation can regulate $\beta$-catenin levels via a proteasome-mediated and adenomatous polyposis coli-independent pathway," Journal of Biological Chemistry, vol. 279, no. 34, pp. 35583-35594, 2004.

[13] R. Nasrallah, J. Clark, J. Corinaldi et al., “Thiazolidinediones alter growth and epithelial cell integrity, independent of PPAR$\gamma$ and MAPK activation, in mouse M1 cortical collecting duct cells," American Journal of Physiology, vol. 298, no. 5, pp. F1105-F1112, 2010.

[14] T. Welbourne, G. Su, G. Coates, R. Routh, K. McCarthy, and H. Battarbee, "Troglitazone induces a cellular acidosis by inhibiting acid extrusion in cultured rat mesangial cells," American Journal of Physiology, vol. 282, no. 6, pp. R1600R1607, 2002.

[15] Y. Guan, Y. Zhang, L. Davis, and M. D. Breyer, "Expression of peroxisome proliferator-activated receptors in urinary tract of rabbits and humans," American Journal of Physiology, vol. 273, no. 6, pp. F1013-F1022, 1997.

[16] H. Zhang, A. Zhang, D. E. Kohan, R. D. Nelson, F. J. Gonzalez, and T. Yang, "Collecting duct-specific deletion of peroxisome proliferator-activated receptor $\gamma$ blocks thiazolidinedioneinduced fluid retention," Proceedings of the National Academy of Sciences of the United States of America, vol. 102, no. 26, pp. 9406-9411, 2005.

[17] H. C. Cheng, T. C. Ho, S. L. Chen, H. Y. Lai, K. F. Hong, and Y. P. Tsao, "Troglitazone suppresses transforming growth factor beta-mediated fibrogenesis in retinal pigment epithelial cells," Molecular Vision, vol. 14, pp. 95-104, 2008.

[18] C. E. Clay, A. M. Namen, G. I. Atsumi et al., "Magnitude of peroxisome proliferator-activated receptor- $\gamma$ activation is associated with important and seemingly opposite biological responses in breast cancer cells," Journal of Investigative Medicine, vol. 49, no. 5, pp. 413-420, 2001.

[19] E. Ito, S. Ozawa, K. Takahashi et al., "PPAR- $\gamma$ overexpression selectively suppresses insulin secretory capacity in isolated pancreatic islets through induction of UCP-2 protein," Biochemical and Biophysical Research Communications, vol. 324, no. 2, pp. 810-814, 2004.

[20] Y. Kanoh, G. Bandyopadhyay, M. P. Sajan, M. L. Standaert, and R. V. Farese, "Thiazolidinedione treatment enhances insulin effects on protein kinase $\mathrm{C}-\zeta / \lambda$ activation and glucose transport in adipocytes of nondiabetic and Goto-Kakizaki type II diabetic rats," Journal of Biological Chemistry, vol. 275, no. 22, pp. 16690-16696, 2000.
[21] L. Yang, C. C. Chan, O. S. Kwon et al., "Regulation of peroxisome proliferator-activated receptor- $\gamma$ in liver fibrosis," American Journal of Physiology, vol. 291, no. 5, pp. G902G911, 2006.

[22] F. Turturro, R. Oliver, E. Friday, I. Nissim, and T. Welbourne, "Troglitazone and pioglitazone interactions via PPAR$\gamma$-independent and -dependent pathways in regulating physiological responses in renal tubule-derived cell lines," American Journal of Physiology, vol. 292, no. 3, pp. C1137-C1146, 2007.

[23] R. F. Husted, R. D. Sigmund, and J. B. Stokes, "Mechanisms of inactivation of the action of aldosterone on collecting duct by TGF- $\beta$," American Journal of Physiology, vol. 278, no. 3, pp. F425-F433, 2000.

[24] R. F. Husted and J. B. Stokes, "Separate regulation of $\mathrm{Na}+$ and anion transport by IMCD: location, aldosterone, hypertonicity, TGF- $\beta 1$, and cAMP," American Journal of Physiology, vol. 271, no. 2, pp. F433-F439, 1996.

[25] M. Desclozeaux, J. Venturato, F. G. Wylie et al., "Active Rab11 and functional recycling endosome are required for Ecadherin trafficking and lumen formation during epithelial morphogenesis," American Journal of Physiology, vol. 295, no. 2, pp. C545-C556, 2008.

[26] A. Masszi, L. Fan, L. Rosivall et al., "Integrity of cell-cell contacts is a critical regulator of TGF- $\beta 1$-induced epithelialto-myofibroblast transition: role for $\beta$-catenin," American Journal of Pathology, vol. 165, no. 6, pp. 1955-1967, 2004.

[27] C. Bocca, F. Bozzo, S. Francica, S. Colombatto, and A. Miglietta, "Involvement of PPAR $\gamma$ and E-cadherin/ $\beta$-catenin pathway in the antiproliferative effect of conjugated linoleic acid in MCF-7 cells," International Journal of Cancer, vol. 121, no. 2, pp. 248-256, 2007.

[28] A. B. Reynolds and R. H. Carnahan, "Regulation of cadherin stability and turnover by p120ctn: implications in disease and cancer," Seminars in Cell and Developmental Biology, vol. 15, no. 6, pp. 657-663, 2004.

[29] F. Drees, S. Pokutta, S. Yamada, W. J. Nelson, and W. I. Weis, " $\alpha$-catenin is a molecular switch that binds E-cadherin- $\beta$ catenin and regulates actin-filament assembly," Cell, vol. 123, no. 5, pp. 903-915, 2005.

[30] S. Zafiriou, S. R. Stanners, S. Saad, T. S. Polhill, P. Poronnik, and C. A. Pollock, "Pioglitazone inhibits cell growth and reduces matrix production in human kidney fibroblasts," Journal of the American Society of Nephrology, vol. 16, no. 3, pp. 638-645, 2005.

[31] B. Guo, D. Koya, M. Isono, T. Sugimoto, A. Kashiwagi, and M. Haneda, "Peroxisome proliferator-activated receptor- $\gamma$ ligands inhibit TGF- $\beta 1$-induced fibronectin expression in glomerular mesangial cells," Diabetes, vol. 53, no. 1, pp. 200-208, 2004.

[32] A. C. Calkin, S. Giunti, K. A. Jandeleit-Dahm, T. J. Allen, M. E. Cooper, and M. C. Thomas, "PPAR- $\alpha$ and $-\gamma$ agonists attenuate diabetic kidney disease in the apolipoprotein $\mathrm{E}$ knockout mouse," Nephrology Dialysis Transplantation, vol. 21, no. 9, pp. 2399-2405, 2006. 

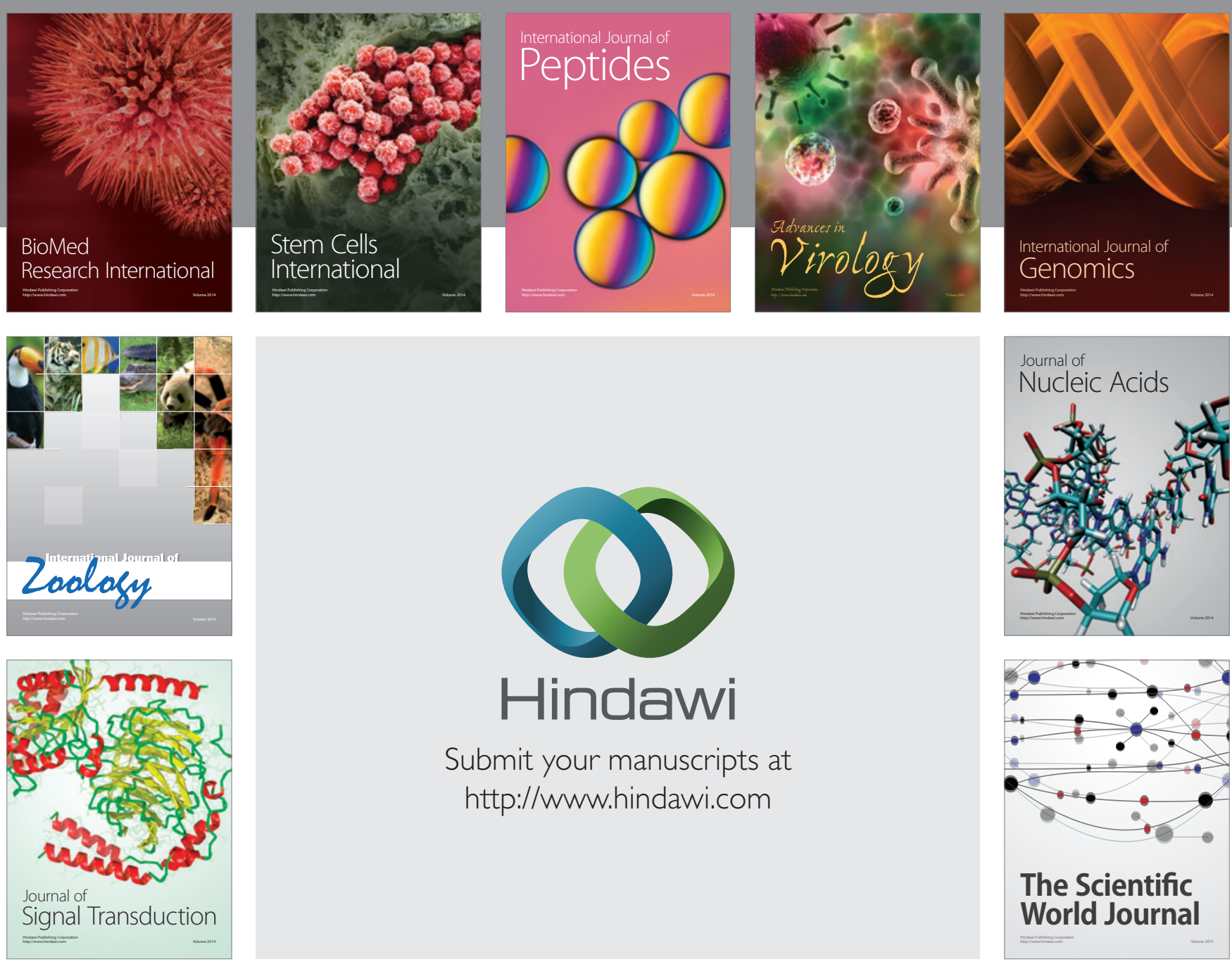

Submit your manuscripts at

http://www.hindawi.com
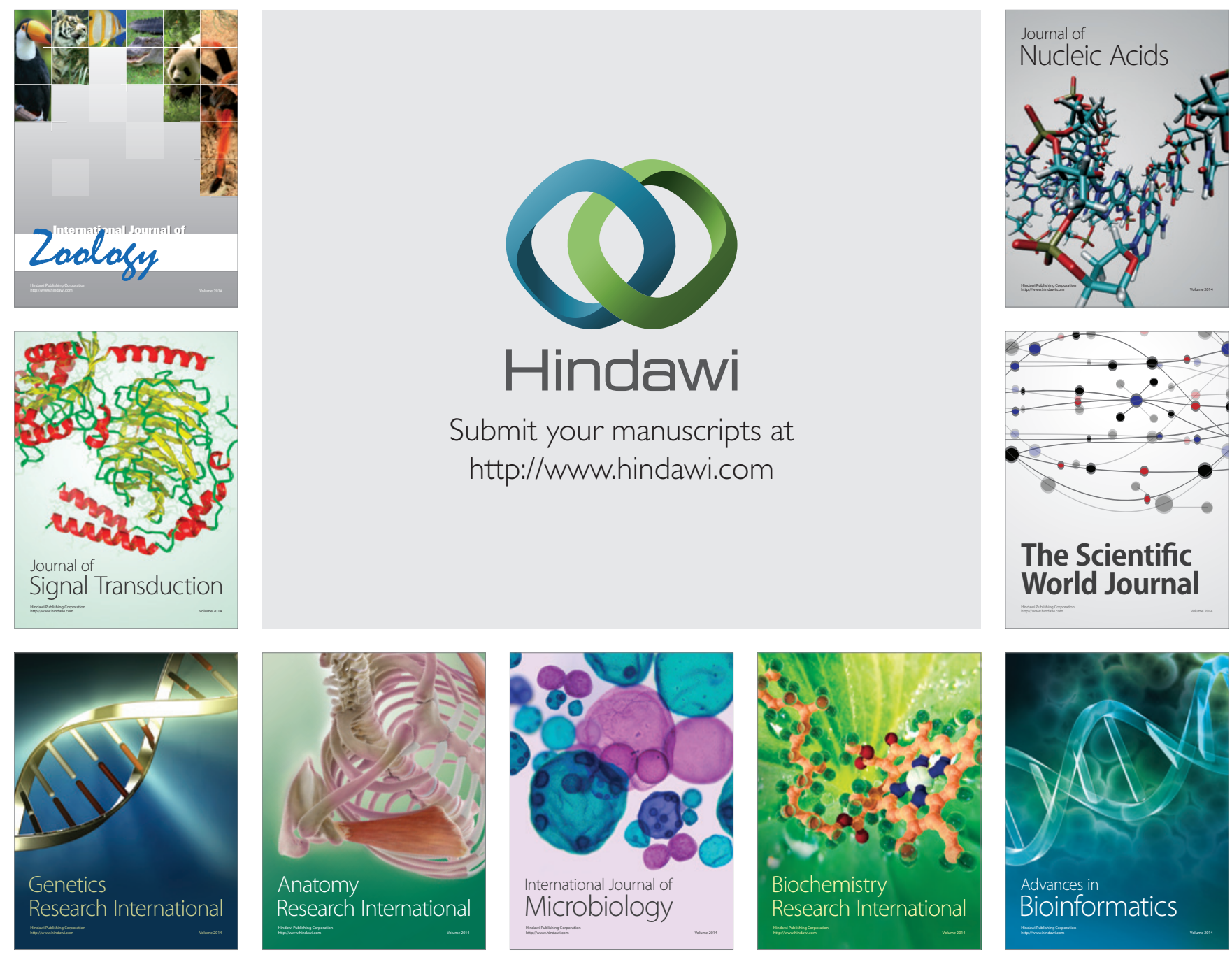

The Scientific World Journal
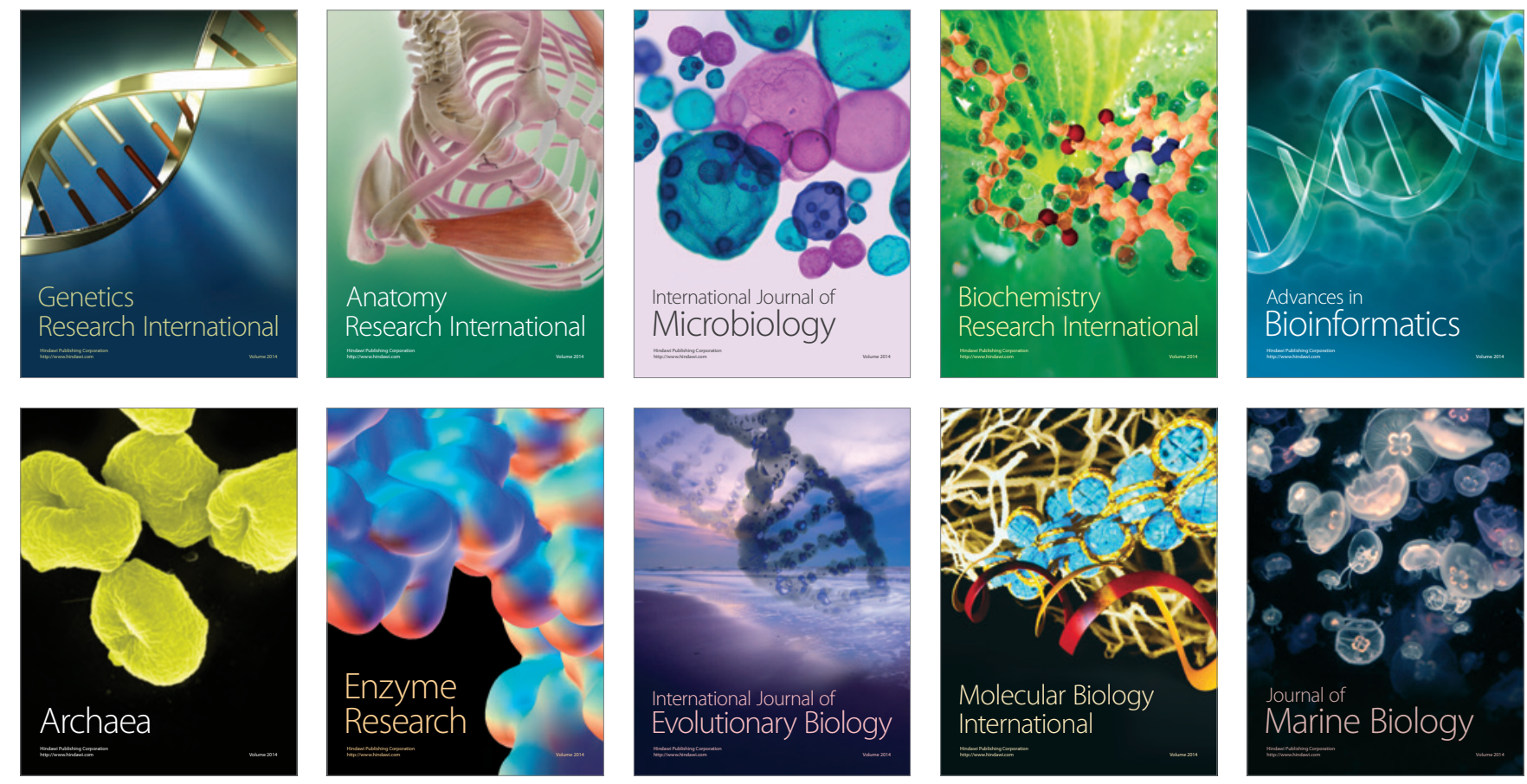